\title{
Interconexões: ecossistemas comunicacionais e processos de criação
}

\section{Interconnects: communicational ecosystems and creation processes}

\section{Interconexiones: ecosistemas comunicacionales y los procesos de creación}

\author{
Rafael de Figueiredo Lopes ${ }^{1}$ \\ Ítala Clay de Oliveira Freitas ${ }^{2}$
}

\section{Resumo}

$\mathrm{O}$ artigo delineia pistas acerca da perspectiva dos ecossistemas comunicacionais propondo sua articulação com processos de criação artística. O objetivo é ampliar possibilidades para compreender aspectos relacionados a interconexões comunicacionais em fluxos criativos na arte contemporânea. A fundamentação teórico-metodológica baseia-se em pressupostos do viés sistêmico e complexo dos Ecossistemas Comunicacionais em diálogo com preceitos teóricos de Processos de Criação, concebidos por Cecilia Almeida Salles. A sistematização da análise apoia-se em dados observados na obra do artista visual amazonense Otoni Mesquita. Como resultado, percebe-se que processos artísticocomunicacionais produzem significados em constante transformação, pela interação dinâmica entre ser humano, ambiente e acoplamentos culturais e tecnológicos.

\begin{tabular}{|c|c|}
\hline \multirow{3}{*}{ 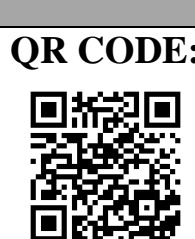 } & Acesse este artigo online \\
\hline & $\begin{array}{l}\text { Website: } \\
\text { http://www.revistas.ufg.br/index.php/ci }\end{array}$ \\
\hline & $\begin{array}{l}\text { DOI: } \\
\text { http://dx.doi.org/10.5216/ci.v20i3.41517 }\end{array}$ \\
\hline
\end{tabular}

Palavras-chave: $\quad$ Ecossistemas Comunicacionais. Processos de Criação. Arte. Otoni Mesquita.

\section{Abstract}

This paper presents ideas about the perspective of communicational ecosystems and processes of artistic creation. Seeks to expand the possibilities is to understand communication interconnections related to creative streams in contemporary art. The theoretical and methodological foundation brings the idea of Communicative Ecosystems in dialogue with theoretical rules of Creation Process, developed by Cecilia Almeida Salles. It is based on data observed in the work of the amazon artist visual Otoni Mesquita. It is clear that artistic and communicational processes produce meanings in constant transformation, the dynamic interaction between human, natural environment, culture and technology.

Keywords: Communicational Ecosystems. Creation Processes. Contemporary Art. Otoni Mesquita.

\section{Resumen}

Este artículo presenta ideas acerca de la perspectiva de los ecosistemas comunicacionales y los procesos de creación artística. Busca ampliar las posibilidades es entender las interconexiones de comunicación relacionados con las corrientes creativas en el arte contemporáneo. El fundamento teórico y

\footnotetext{
${ }^{1}$ Doutorando em Sociedade e Cultura na Amazônia pela Universidade Federal do Amazonas (UFAM), mestre em Ciências da Comunicação (UFAM) e bacharel em Comunicação Social (UFRR). Bolsista da Capes. E-mail: rafaflopes@bol.com.br.

${ }^{2}$ Doutora em Comunicação e Semiótica pela Pontifícia Universidade Católica de São Paulo (PUC-SP), professora da Faculdade de Informação e Comunicação e do Programa de Pós-Graduação em Ciências da Comunicação da Universidade Federal do Amazonas, onde coordena a linha de pesquisa em Linguagens, representações e estéticas comunicacionais. E-mail: iclayfreitas@hotmail.com.
} 
metodológico trae la idea de ecosistemas comunicacionales en el diálogo con las normas teóricas del proceso de creación, desarrollados por Cecilia Almeida Salles. Se basa en los datos observados en la obra del artista visual amazónico Otoni Mesquita. Como resultado de ello, es evidente que los procesos artísticos y de comunicación producen significados en constante transformación, la interacción dinámica entre los seres humanos, el medio ambiente, la cultura y la tecnología.

Palabras clave: Ecosistemas Comunicacionales. Procesos de Creación. Arte Contemporáneo. Otoni Mesquita.

\section{UMA BREVE INTRODUÇÃO AOS ECOSSISTEMAS COMUNICACIONAIS}

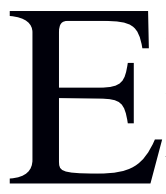
m princípio, ao embarcarmos na viagem dos ecossistemas comunicacionais, por não ter a pretensão em ser um "conceito formal", temos a impressão de estarmos num bote, à deriva, na imensidão do mar. Afinal, como é possível pensar e fazer ciência sem uma matriz epistemológica fixa para garantir o rigor dos estudos, sem uma sistematização formal e estruturada, com métodos tradicionais, procedimentos práticos, resultados, sem a credibilidade de um selo que lhe ateste cientificidade?

Responder a esses questionamentos não é fácil, mas talvez acione o início de um pensamento em cadeia, no intuito de investirmos no empreendimento de construções que nunca serão finalizadas e mesmo assim não perdermos o prazer de continuar a edificá-las. Erguer uma ponte que não leva a outra margem do rio, mas propõe a possiblidade do rio ter uma terceira margem, ou múltiplas pontes para múltiplas margens, ou ainda arquitetar uma casa sem teto, uma universidade sem chão. Mas, ao pensarmos desse modo, será que as pontes serão seguras, as casas habitáveis e as universidades produzirão conhecimento? Essas alegorias servem de metáfora para nos sugerir que não há garantias e os ecossistemas comunicacionais não pretendem se esgotar a uma teoria ou sistema fechado com a obrigatoriedade de uma aplicação prática.

É por isso, que, ao denominá-lo, nos referimos como sendo uma “ideia”, ou como uma "perspectiva do olhar", para a qual, por enquanto, temos apenas pistas, reflexos muitas vezes desconexos. E, possivelmente, sua peculiaridade seja em se manter assim, pois no momento em que tivermos o seu mapa detalhado, poderemos constatar que o baú do tesouro é apenas uma arca vazia e, na frustração, esquecermos que a trajetória foi o mais importante e significativo no processo de descoberta. Desse modo, enquanto um pressuposto que transita articulando diferentes sistemas e, por isso, complexo de se compreender, os ecossistemas comunicacionais podempromover experimentações com nuanças impensadas para revestir as polissêmicas superfícies da construção do conhecimento. 
Ecossistemas comunicacionais, entretanto, já é uma proposição "institucionalizada", haja vista que é a área de concentração do Programa de Pós-Graduação em Ciências da Comunicação da Universidade Federal do Amazonas (PPGCCOM/UFAM) ${ }^{3}$. O curso, iniciado em 2008, foi o primeiro Programa de Pós-Graduação na área de Comunicação do Norte do Brasil a ser aprovado pelaCoordenação de Aperfeiçoamento de Pessoal de Nível Superior (Capes). Atualmente, suas investigações são guiadas por duas linhas de pesquisa: Redes e processos comunicacionais; e Linguagens, representações e estéticas comunicacionais.

Mesmo diante dessa configuração, possivelmente, ainda pairem as dúvidas sobre as ferramentas conceituais para auxiliar na compreensão de ecossistemas comunicacionais, sobre como essa proposta se articula com outras áreas do conhecimento ou como evidenciá-la em estudos teóricos e empíricos. Entretanto, como já foi ressaltado, a ideia aqui não é aplicar uma fórmula para encontrar o resultado do problema, mas apontar pistas, trilhas e caminhos em um campo emergente da comunicação.

O que precisa estar claro, é que mesmo numa aparente desordem (ou considerando a desordem como regra), existe uma sistematização com critérios científicos, de significação e até mesmo não desconsiderando possibilidades pragmáticas. Seu rigor está no vigor de aceitar quemesmo em um sistema aberto ou cambiável há critérios relevantes e recorrentes. Esse raciocínio abstrato é perfeitamente possível de ser exemplificado, por exemplo, ao pensarmos na organicidade do funcionamento do corpo humano ou no caos harmônico do universo.

Mas, paraobjetivarmos a discussão diante da proposta deste artigo, trataremos do assunto de modo menos filosófico e mais didático.Assim sendo, o desenvolvimento da perspectiva ecossistêmica na UFAM, parte de investigações que consideram a complexidade sistêmica e informacional dos fenômenos comunicativos, "propondo estudos sobre osprocessos de organização, transformação e produção das mensagens conformadasna cultura a partir das interações entre sistemas sócio-culturais-tecnológicos" (MONTEIRO; ABBUD; PEREIRA, 2012, p. 09). É um campo de estudos que que encontrou no contexto amazônico "um espaço emblemático para a exploração das interferências mútuas entre as diferentes esferas que regem a vida, a comunicação e a cultura" (IBID, p. 10).

Embora outras áreas de estudo ou conceitos também se aproximem deste viés (e até o inspirem), a exemplo do Ecossistema Comunicativo, a partir da Educomunicação; a ideia de Novo Sensório, desenvolvida por Walter Benjamin; o Pensamento Complexo, por Edgar Morin;

\footnotetext{
${ }^{3}$ Disponível em: 〈http://www.ppgccom.ufam.edu.br/index.php/apresentacao $>$ Acesso em: 08 maio 2016.
} 
Rizoma, por Gilles Deleuze e Felix Guattari, entre outros, a proposta do PPGCCOM/UFAM apresenta características próprias, num constante processo de construção.

Por isso, as investigações no âmbito dos ecossistemas comunicacionais têm ganhado múltiplas abordagens na UFAM, a partir das diferentes visões e experiências de pesquisadores dedicados a essa vertente aberta da comunicação. Como exemplo, podemos citar a visão do Prof. Dr. Gilson Vieira Monteiro, que coordena o grupo Interfaces (UFAM/CNPq), e trabalha a ideia de ecossistemas comunicacionais considerando interconexões da relação entre os sujeitos, processos sociais, a natureza e os acoplamentos tecnológicos ${ }^{4}$;uma linha de pensamento semelhante a do Prof. Dr. Sandro Colferai ${ }^{5}$ (Universidade Federal de Rondônia/UNIR),que usa a própria Amazônia como metáfora de ecossistema comunicacional, aproximando o conhecimento científico tradicional dos saberes regionais; já a Profa. Dra. Mirna Feitosa Pereira, que coordena o grupo Mediação (UFAM/CNPq), estuda as relações de interação e interdependência entre os sistemas comunicativos e o ambiente pelo viés da semiótica $^{6}$. Outros professores e egressos do PPGCCOM também têm se debruçado sobre os estudos dos fenômenos comunicativos pela perspectiva ecossistêmica comunicacional, e as publicações sob esse prisma, aos poucos, começam a ganhar espaço no meio acadêmico.

Neste artigo, em função de um olhar dirigido para a obra de Otoni Mesquita, que representa o contexto amazônico, em sua arte de expressão multilinguagem, optou-se por seguir a linha de pensamento ecossistêmico comunicacional de Colferai (2012), orbitando numa abordagem que se articula considerando a corporeidade das relações, as tecnologias, as subjetividades sociais e o ambiente. Portanto, dialoga com múltiplas conceituações teóricas e campos do conhecimento, convidando à imersão sensorial e à complexidade. $\mathrm{O}$ autor explica que para apreender e desenvolver essa ideia ecossistêmica, recorreu a conceitos dos filósofos chilenos Francisco Varela e Humberto Maturana, como enação, ao considerar a inseparabilidade entre ser humano e natureza, e autopoiese, ou seja, a capacidade dos sistemas vivos e suas estruturas estarem em constante autoprodução e autorregulação, mantendo

\footnotetext{
${ }^{4}$ Em Ecossistemas comunicacionais: uma visão prática (MONTEIRO; DANTAS, 2012), busca-se demonstrar como os ecossistemas comunicacionais possibilitam a mobilização social no interior do Amazonas. Por meio de um estudo de campo, realizado em uma colônia de pescadores, no município de Tefé (AM), foi possível mapear práticas de comunicação e aparatos tecnológicos incorporadas ao cotidiano dessa comunidade.

${ }^{5}$ O pesquisador é professor do curso de Comunicação Social da UNIR, mas integra o grupo de pesquisa Interfaces, da Universidade Federal do Amazonas, instituição na qual obteve o título de doutor em Sociedade e Cultura na Amazônia, com a tese: Um jeito amazônida de ser mundo. A Amazônia como metáfora do ecossistema comunicacional: uma leitura do conceito a partir da região, ver Colferai (2014).

${ }^{6}$ Pereira (2011)trabalha a caracterização de aportes para a abordagem dos ecossistemas comunicacionais a partir de um conjunto de concepções semióticas inspiradas em conceitos de semiose, semiosfera e nas discussões propostas pela ecossemiótica e pela cibernética, voltando-se para o estudo das relações de interdependência entre os sistemas participantes da comunicação e o ambiente onde se inserem, em constante ação sígnica.
}

Comun. \& Inf., Goiânia, GO, v. 20, n. 3, p. 132-147, out./dez. 2017 
interações entre seus próprios elementos e na relação com outros sistemas, além do pensamento complexo, de Edgar Morin, e da ecologia dos saberes, de Boaventura Sousa Santos, em favor de uma ciência não paradigmática.

Nesse sentido, Colferai (2014) defende que a comunicação se estabelece por subjetividades e materialidades efetivadas entre vivências, contradições e compreensões transitórias, pelas quais o ser humano apreende ao atuar com o meio onde se insere, muitas vezes através de acoplamentos tecnológicos ou de interfaces sensoriais, que também constituem o processo de formação cultural e codificação de linguagens.

Ter como princípio os saberes conectados implica em compreender que no Ecossistema Comunicacional não há separações entre as organizações sociais e os significados nelas postos em circulação, o ambiente físico-natural e as novas percepções e sensibilidades acionadas pela ampliação da comunicação e circulação de informações proporcionada pelas novas tecnologias. (COLFERAI, 2014, p. 59).

Desse modo, conforme Colferai (2014), há uma plasticidade favorável à conexão entre ser humano, ambiente e aparatos tecnológicos, e o que vemos, ouvimos e sentimos (seja na experiência real ou virtual, individual ou na interação social, pelas telas de TV, celulares, ipods, jogos eletrônicos e etc.) provocam reações no sistema nervoso criando novas conexões neuromusculares e cognitivas, fazendo com que os aspectos biológicos, psíquicos, sociais, do ambiente e o aparato tecnológico tornem-se pontos de conexão em simbiose. É nessa dinâmica, segundo o autor, que proporciona-se a expansão de corpos e sentidos, por atuações diversas e complexas. A compreensão de ecossistemas comunicacionais implica ter essa flexibilidade de entendimento e percepçãoe, por isso, quem se propõe a pesquisar por esse viés não deve pensar, necessariamente, em uma aplicação prática, como se essa ideia fosse um conceito fechado, mas exercitar a busca de multiplicidades e acoplamentos, permitindo que a criatividade e os afetos ganhem espaço na produção do conhecimento científico.

A abertura e a subjetividade presentes na leitura que proponho para o Ecossistema Comunicacional encontram lastro em pensadores que propõem a superação de um paradigma tradicional de Ciência e implicam em manter à distância qualquer pretensão de tudo alcançar. Isso torna descabido considerar que o conceito pode ser simplesmente aplicado a todas as demandas de pesquisa surgidas quando se tematiza as intersecções entre sociedade, natureza e tecnologias da comunicação e informação. (COLFERAI, 2014, p. 199).

\section{A COMUNICAÇÃO NOS PROCESSOS CRIATIVOS NA ARTE}


A arte é subjetiva, e em nossa concepção não é possível explicá-la por fórmulas ou conceituações estanques. Por isso, ao abordarmos aspectos dessa complexa atividade humana, tecida por fios da razão e da sensibilidade, precisamos compreender um pouco sobre sistemas que envolvem a mente. Nesse sentido acreditamos que haja uma harmonia entre a nossa compreensão ecossistêmica comunicacional e os processos criativos da arte.

A preocupação em distinguir consciente de inconsciente acompanha os filósofos desde a antiguidade, mas conforme o físico teórico norte-americano Leonard Mlodinow (2013) só a partir do século XIX é que os cientistas passaram a dar mais atenção aos estudos envolvendo a fisiologia e a psicologia. $\mathrm{O}$ autor destaca o trabalho visionário de William Carpenter, o primeiro estudioso a escrever que a ação mental ocorre simultaneamente em níveis conscientes e inconscientes, e de Charles Sanders Peirce, quem descobriu que o inconsciente desenvolve conhecimentos ignorados pela consciência, ao inventar experimentos que se tornaram ferramentas padrão na sondagem da mente, embora Mlodinow reconheça a importância histórica de Freud na popularização dos estudos do inconsciente.

Desde então, os estudos evoluíram e hoje, com os progressos da ciência, é possível mapear rotas complexas realizadas pelo cérebro. Conforme Mlodinow (2013) estima-se que apenas $5 \%$ de nossas funções cognitivas sejam conscientes o restante é inconsciente, porém, esses $95 \%$ exercem influência subliminar em nossos atos e pensamentos.

A evolução nos deu uma mente inconsciente porque é ela que permite nossa
sobrevivência num mundo que exige assimilação e processamento de energia
tão maciços. Percepção sensorial, capacidade de memória, julgamentos,
decisões e atividades do dia a dia parecem não exigir esforço - mas isso só
porque o esforço demandado é imposto sobretudo a partes do cérebro que
funcionam fora do plano da consciência. (MLODINOW, 2013, p. 31).

Segundo Mlodinow (2013) outras espécies animais também apresentam atividades cerebrais em níveis conscientes e inconscientes, mas, no caso da espécie humana a necessidade de interação social foi propulsora para a evolução da inteligência. Conforme o autor, diferente de outras espécies, a capacitação do ser humano para ocomportamento social, pode ser decorrente de uma mutação no cérebro, há cerca de 50 mil anos (sem que tenha havido alteração na anatomia), ocorrida em uma época em que os indivíduos começaram a pescar, caçar e perseguir animais ferozes no intuito de lutar em coletividade pela sobrevivência.

Mais ou menos na mesma época, começaram também a construir estruturas para abrigo e a criar arte simbólica e complexos sítios funerários. De repente descobriram como se juntar para caçar mamutes lanudos e começaram a participar de cerimônias e rituais que são os rudimentos do que hoje 
chamamos de cultura. Num breve período de tempo, o registro arqueológico de atividades humanas mudou mais do que havia se alterado no 1 milhão de anos anteriores. (MLODINOW, 2013, p. 76).

O autor nos indica que essa transformação começou a conformar as bases da cultura, da complexidade ideológica e cooperação coletiva da sociedade, do mesmo modo que nela estão as raízes da arte e a gênese do processo criativo. Contudo, tratar da arte e da criatividade, por si só, é uma tarefa hercúlea, e neste artigo estamos discutindo apenas alguns aspectos que envolvem processos criativos e comunicativos, portanto, nossa abordagem é apenas um pequeno recorte de um universo riquíssimo e que pode ser explorado por diferentes perspectivas.

Nossa proposta é ampliar as possibilidades de compreender aspectos relacionados à interconexões comunicacionais, em fluxos criativos na arte contemporânea, umaleitura que, segundo Salles (2010), não pode ser feita de forma linear como costuma-se fazer ao estudar a história da arte desde a pré-história à modernidade. Afinal, conforme a autora, o artista contemporâneo desenvolve seu trabalho a partir de intrincadas relações em rede, criando obras em movimento, conceitualmente abertas e flexíveis, recebendo influências diversas.

\begin{abstract}
A criação como rede pode ser descrita como um processo contínuo de interconexões instáveis, gerando nós de interação, cuja variabilidade obedece a alguns princípios direcionadores. Essas interconexões envolvem a relação do artista com seu espaço e seu tempo, questões relativas à memória, à percepção, recursos criativos, assim como os diferentes modos que se organizam as tramas do pensamento em criação. $\mathrm{O}$ artista deixa rastros desse percurso nos diferentes documentos do processo criativo. (SALLES, 2010, p. 215).
\end{abstract}

Nesse sentido, Salles (2010), acredita que o processo de criação é uma manifestação comunicacional, ao relacionar o diálogo do artista com ele mesmo e suas ideias, com a obra em criação, com os expectadores, com a crítica, enfim, estabelece um circuito de interlocuções que vão gerar transformações e ressignificações.

Os estudos a respeito dos processos de criação artística, conforme Salles (2010), não pretendem desvendar toda a complexidade do percurso do artista ou do significado de sua obra ou ainda encontrar uma fórmula explicativa para ser aplicada, mas por meio da observação de índices estabelecer relações, em pesquisas de natureza indutiva. Portanto, o pesquisador deve procurar abordagens teóricas adequadas a objetos de estudo em movimento, pois a busca é uma compreensão do processo. Desse modo a observação e o levantamento de hipóteses é fundamental para captar os fluxos do artista. É necessário um olhar inter-relacional, porque a ação do artista não é linear, tem ritmos, picos, curvas e nós. Uma construção que vai se tramando

Comun. \& Inf., Goiânia, GO, v. 20, n. 3, p. 132-147, out./dez. 2017 
num processo contínuo de interconexões e interações no tempo e no espaço. Conforme Salles (2010) o processo de criação em qualquer manifestação artística pode ser investigado pelos documentos elaborados durante o desenvolvimento das obras ou realizações que repercutem esse processo. Podem ser esboços, manuscritos, relatos, diários, maquetes, vídeos, fotografias, o próprio local onde o artista realiza seu trabalho apresenta pistas interessantes. A investigação transita num percurso singular que, segundo a autora, "é feito de palavras, imagens, sons, gestualidade etc.” (SALLES, 2010, p. 102).

Desse modo, percebemos a importância do "corpomente" e do ambiente ${ }^{7}$ como força motriz no ciclo comunicacional e na criação artística. Para Greiner (2005) o corpo não é apenas um recipiente e transmissor de informações, mas um organismo transformador em constante evolução pela contaminação entre o fluxo informacional que percorre seu contexto sensitivo interno e externo. As experiências decorrentes dessas relações geram comunicação, percepção e relação.

Greiner (2005) faz uma reflexão sobre ideias e conceitos acerca do corpo em diferentes contextos históricos e várias áreas do conhecimento, com mais ênfase nas perspectivas teóricas das décadas de 1980/90, responsáveis pelas teorias do corpo contemporâneas mais significativas. A autora propõe pensar o corpo como um sistema complexo e interativo e não apenas como um instrumento, com um lado biológico e outro cultural, ou material e mental.

Possivelmente, essa dicotomia tenha explicação na gênese etimológica da palavra corpo, segundo Greiner (2005), ao explicar que, do latim, corpus ou corporis se referem ao corpo morto, em oposição a alma ou ânima que expressa o corpo vivo. A autora aponta evidencias que conectam o processo co-evolutivo do corpo e do ambiente com exemplos de fluxos conectivos entre nações, línguas e culturas, redefinindo os mapas de "fronteiras dramáticas" das "geografias imaginativas". Isso porque o corpo é provido de uma dramaturgia que dá sentido e coerência ao fluxo incessante de informações entre o corpo e o ambiente.

O modo como ela se organiza em tempo e espaço é também o modo como as imagens do corpo se constroem no trânsito entre o dentro (imagens que não se vê, imagens-pensamentos) e o fora (imagens implementadas em ações) do corpo organizando-se como processos latentes de comunicação. (GREINER, 2005, p. 73)

\footnotetext{
${ }^{7}$ Estamos trabalhando com a ideia de "corpo mente" e do ambiente, a partir da Teoria Corpomídia, formulada pelas pesquisadoras Christine Greiner e Helena Katz, do Centro de Comunicação das Artes do Corpo, vinculado ao Programa de Pós-Graduação em Comunicação e Semiótica da PUC-SP, que propõe pensar o corpo como um organismo ecológico, ou seja, inseparável da relação com o seu ambiente.
}

Comun. \& Inf., Goiânia, GO, v. 20, n. 3, p. 132-147, out./dez. 2017 
Em relação a arte, Greiner $(2005)^{8}$ diz que o corpo muda cada vez que percebe o mundo, despertando metáforas mutantes que geram novas ações, caracterizando um "corpo artista" a partir da inspiração na hipótese levantada pelo neurocientista Vilayanur S. Ramaschandran, para quem a arte (como fenômeno mental) teria uma função fundamentalmente necessária para sobrevivermos. "Assim como a atividade sexual e a experiência da morte (próxima ou anunciada), a atividade estética representaria em nosso processo evolutivo, uma ignição para a vida" (GREINER, 2005, p. 111).

\section{ARTES VISUAIS NO AMAZONAS}

Freitas (2010) aponta que os registros sobre manifestações culturais e expressões artísticas no Amazonas pela historiografia tradicional, em geral, remontam concepções ideológicas, sociais, geográficas, urbanísticas, políticas e econômicas centradas em aspectos que atendem aos interesses das "forças dominantes". Desse modo, uma amalgama de manifestações e criações, ao serem marginalizadas pelo discurso do "poder instituído", foram sendo esquecidas.

O viver amazônico e mais especificamente a vida cultural e artística em Manaus, ainda ressente-se de abordagens de mestiçagens, as quais possam apresentar outras formas de articulação cultural, outros nexos de sentido, outras veias de significado. Teias nas quais a Amazônia colonial possa ser vista a partir de convivências e negociações de poder, o período do ciclo da borracha não seja apenas sinônimo de opulência e esbanjamento frívolos, e a depressão econômica não necessariamente tenha impossibilitado a vida cultural na cidade. (FREITAS, 2010, p. 27)

Entretanto, reforça Freitas (2010), a iniciativa de alguns historiadores e pesquisadores têm buscado uma reconciliação ética e social, pelo resgate histórico contextualizado e crítico, como Edineia Dias, José Aldemir de Oliveira, Neide Gondim, Amálio Pinheiro, José Ribamar Mitoso, Márcio Páscoa e Otoni Mesquita, com abordagens que trouxeram outras perspectivas e a ampliação de questionamentos em relação ao universo cultural e artístico amazonense e manauara.

Segundo Páscoa (2011) as informações de registros sobre a produção de artes visuais no Amazonas (especialmente a fotografia, a pintura, a escultura e a decoração) surgem por volta de 1850, a partir do Ciclo da Borracha, com repercussão do trabalho de fotógrafos, escultores

\footnotetext{
${ }^{8}$ Segundo Greiner (2005) o corpo é sujeito físico, mental e ambiental, pois está em permanente processo de evolução com o ambiente natural e cultural em que se insere, contrapondo-se a noção cartesiana na qual corpo, mente e ambiente estão dissociados.
}

Comun. \& Inf., Goiânia, GO, v. 20, n. 3, p. 132-147, out./dez. 2017 
e pintores decorativos de casas e prédios públicos que vinham principalmente da Europa e do Rio de Janeiro.

Entre as décadas de 1960 e 1970 o Clube da Madrugada foi o movimento cultural de maior efervescência no Amazonas. O grupo vanguardista, voltado para a renovação estética, era formado por artistas plásticos, poetas, cineastas, músicos e intelectuais que buscava divulgar novos talentos e incentivar a produção de seus integrantes, promovendo exposições, conferências, publicações literárias, festivais de cinema e programas de rádio. Conforme Páscoa (2011) o movimento tinha um caráter "anárquico libertário" no intuito de incentivar as expressões culturais regionais e criticar a supervalorização dada aos modelos culturais importados.

A partir das ideias difundidas pelo Clube da Madrugada o cenário artístico em Manaus ganhou mobilidade e originalidade. Depois surgiram nomes reconhecidos nacional e internacionalmente como Zeca Nazaré (artista gráfico), Van Pereira (ilustrador) e Hahnemann Bacelar (expressionista). Outro artista marcante é Roberto Evangelista que contribuiu para o panorama artístico amazonense contemporâneo com suas criações experimentais de arte conceitual e videoinstalação, participando de eventos importantes como a Bienal de São Paulo, além de exposições nos Estados Unidos e na Europa.

Contudo, os artistas, as artes e as manifestações culturais da Amazônia, no senso comum, com raras exceções, ainda são marcados pelo exotismo (pela construção dos olhares "estrangeiros" e muitas vezes sustentadas pela espetacularização do "autoexotismo"). Isso, conforme Paes Loureiro (2015), decorre de uma colonização cultural do imaginário, construída desde relatos dos viajantes do século XVI até o reforço de clichês e estereótipos pelos meios de comunicação atuais. Desse modo, é importante que a compreensão da arte produzida na região não seja limitada a padrões pré-concebidos, mas contextualizada e respeitada em sua diversidade. E nesse sentido, a arte de Otoni Mesquita tem papel fundamental, atuando de forma militante e contribuindo para a quebra de preconceitos, pela valorização da cultura regional e a consciência ecológica. Um artista multimídia, que se mantém como um estandarte da resistência, sendo um dos últimos remanescentes do Clube da Madrugada, na luta pela expressão e reconhecimento da arte amazônida.

Otoni Mesquita ${ }^{9}$ é jornalista, ilustrador, artista plástico, contista, historiador e professor universitário. É considerado um dos mais um dos atuantes artistas amazonenses

\footnotetext{
${ }^{9}$ As informações sobre a trajetória profissional de Otoni Mesquita têm base no Sistema Lattes. Disponível em: <http://buscatextual.cnpq.br/buscatextual/visualizacv.do?id=K4794890A0>. Acesso em 22 mar. 2016.
}

Comun. \& Inf., Goiânia, GO, v. 20, n. 3, p. 132-147, out./dez. 2017 
contemporâneos e se destaca por sua postura crítica em relação a sociedade e pela inventividade do universo imagético que representa em suas criações, voltadas principalmente à natureza e aos mitos regionais, além disso, é uma das personalidades do meio artístico local mais reportadas pelos meios de comunicação tradicionais do Amazonas.

Nascido no município de Autazes (AM), em 1953, mudou-se para Manaus com pouco mais de um ano de idade e teve uma infância marcada pelo exercício livre e criativo do desenho ${ }^{10}$. Atua como artista plástico desde 1975, desenvolvendo obras em variados suportes, gêneros e materiais. Graduou-se em Comunicação Social (Jornalismo) pela Universidade Federal do Amazonas (1979) e em Belas Artes (Gravura) pela Universidade Federal do Rio de Janeiro (1983). É mestre em Artes Visuais (1991) pela Universidade Federal do Rio de Janeiro e doutor em História Social (2005) pela Universidade Federal Fluminense. Desde 1994 é professor do Departamento de Artes da Universidade Federal do Amazonas e integra o Núcleo de Antropologia Visual da UFAM. Seu currículo conta com a participação em mais de cem exposições coletivas e individuais, inclusive, com a obtenção de prêmios em Salões de Arte, além de ter publicado dois livros sobre história e arquitetura de Manaus e também atuado como Coordenador do Patrimônio Histórico da Secretaria de Cultura do Estado do Amazonas.

\section{DINÂMICA ECOSSISTÊMICA COMUNICACIONAL DE OTONI MESQUITA}

Para a discussão que se segue, faremos um pequeno mosaico em torno do chamado Ciclos do Eldorado, que não compreende uma fase específica da obra de Otoni Mesquita, mas é um tema recorrente de sua trajetória artística, que esporadicamente volta à tona e é marcado por exposições, atividades extensivas à comunidade além de reflexões cotidianas do artista divulgadas na mídia tradicional e nas redes sociais. O recorte foi feito a fim de objetivarmos a proposta conceitual deste artigo, podendo ser desdobrado, problematizado e aprofundado em trabalhos posteriores.

No processo artísticode Ciclos do Eldorado expressam-se manifestações de diferentes linguagens como pintura, gravura, instalação, indumentária, vídeo e performance. Nossa estratégia metodológica é baseada na ideia de "arquivos de criação", de Salles (2010), na qual por meio da observação de documentoso pesquisador estabelece relações e hipóteses. Estamosconsiderando como material de análise as fotos, vídeos e textos expostosno álbum

\footnotetext{
${ }^{10}$ Informações sobre o trajeto pessoal e o processo criativo do artista. Disponível em:

<http://tudoearteounao.blogspot.com.br/2008/09/arte-de-otoni-mesquita.html> Acesso em: 22 mar. 2016.
}

Comun. \& Inf., Goiânia, GO, v. 20, n. 3, p. 132-147, out./dez. 2017 
Memória da Exposição, uma espécie de "museu virtual” que o artista mantém em sua página no Facebook ${ }^{11}$, composto pelo portfólio das exposições realizadas em Ciclos do Eldorado, informações técnicas, atividades extensivas e experiências de bastidores. Para Salles (2010) não é necessário organizar uma cronologia, a pesquisa pode ser desenvolvida pela maneira de aproximação com o material de análise.

A pergunta que se faz diante da documentação estudada é: o que esses dados nos oferecem sobre o processo de criação? A partir do estabelecimento de relação entre os diferentes registros, associado às singularidades do olhar do pesquisador, se chega a alguns focos dos processos dos artistas estudados. (SALLES, 2010, p. 4).

Conforme Salles (2010) a mobilidade do ambiente da web expande as possibilidades de discutir novas perspectivas de processos criativos ou redes de criação.E, nesse sentido, o álbum Memória da Exposição, apresenta o processo de Ciclos do Eldorado, a reflexão do próprio artista sobre a sua relação com essa temática, deixando evidentes as múltiplas interações entre as linguagens artísticas e seus fluxos comunicacionais.

A temática propõe inúmeros questionamentos sobre o processo de colonização da Amazônia, no qual Otoni Mesquita critica a forma de ocupação da região e a supressão das culturas ancestrais a partir da disseminação e manutenção da ideologia etnocêntrica europeia até os dias atuais. Além da questão humana o foco do artista é discutir questões ambientais e políticas, sobretudo, o avanço da devastação da floresta em nome de um "suposto desenvolvimento econômico". Como metáfora poética, Otoni Mesquita muitas vezes pinta plantas com tinta dourada e cria instalações com essas peças para simbolizar que a verdadeira riqueza não é o ouro da "mitológica cidade perdida"12, que aguçou a ganância dos exploradores europeus a partir do século XVI, mas é o verde, a natureza, a Floresta Amazônica.

Só nessas observações iniciais já é possível relacionar um pensamento que perpassa entre o artista, o historiador, o político e o ecologista. Um discurso que além da poética visual é explicitado pelo artista em vídeos, narrados por ele mesmo, explicando algumas instalações,

\footnotetext{
${ }^{11}$ Acervo virtual do artista, visualizado no álbum "Memória da Exposição", no Facebook. Disponível em: <https://www.facebook.com/otoni.demesquita/media_set?set=a.2502746297120.2114560.1506846464\&type=3> Acesso em: 20 abr. 2016

${ }^{12}$ Eldorado é uma mítica cidade de ouro perdida na selva sul-americana, perseguida desde a chegada de Colombo à América, estimulando a exploração financeira do "novo território" ao mesmo tempo que ocasionou embates brutais entre estilos de vida e crenças, provocando o processo de colonização dos povos ameríndios. A busca por esse local que jamais fora encontrado tem origem em uma lenda difundida entre tribos da região, sobre um soberano que cobria o corpo com pó de ouro pela manhã e se banhava em um lago sagrado todas as noites. Disponível em: <http://www.bbc.com/portuguese/noticias/2013/01/130121_pesquisa_mito_eldorado_mv.shtml>. Acesso em: 22 abr. 2016.
}

Comun. \& Inf., Goiânia, GO, v. 20, n. 3, p. 132-147, out./dez. 2017 


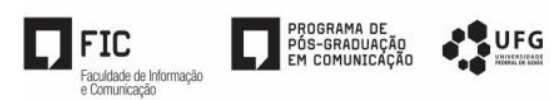

para as quais além de descrever os materiais e as técnicas utilizadas em sua confecção, expõem seus intensões conceituais.

Em busca do Eldorado (2007) foi a primeira exposição sobre o tema, com reflexões e releituras visuais de criações do artista desde 1984, e realizada no Atelier Vila Venturosa, no Rio de Janeiro. Nessa fase o artista trabalhou uma série de gravuras feitas em metal com imagens que remetiam a referências da cultura pré-colombiana e uma pesquisa cromática que buscava uma tonalidade de dourado que não fosse apenas material, mas traduzisse uma atmosfera sensorial do "Eldorado". Algumas pinturas são elaborações alegóricas sobre templos na floresta, mas que também sugerem grandes catedrais de cidades europeias, fazendo uma analogia das riquezas minerais que eram levadas da Amazônia e questionando o processo violento que dizimou milhares de indígenas. Há também a presença das "Personas", pinturas de figuras híbridas compostas por formas humanas, animais e míticas, com inspiração em grafismos da etnia Carajá e indumentária da etnia Ticuna, e que seriam a interpretação do artista para o que ele chama "sincretismo amazônico".

Achados do Eldorado (2012/2014) foi a segunda exposição sobre o tema, percorreu três cidades brasileiras e permitiu a ampliação da experimentação visual com papel reciclado, relevos, arte digital, pinturas e materiais vegetais, como folhas e galhos. O trabalho foi exposto na Galeria de Arte do Sesc Amazonas, em Manaus, em 2012, e no ano seguinte agregou outros elementos e foi exposta no $32^{\circ}$ Salão de Arte do Pará, no Museu Emílio Goeldi, em Belém (2013). Uma das peças dessa exposição, "Oferendas da Floresta", foi apresentada na exposição Amazônia Ciclo de Modernidade, no Palácio da Justiça, em Manaus (2014), e no mesmo ano integrou a exposição Pororoca, no MAR, Museu de Arte do Rio, sendo adquirida para o acervo do museu.

A terceira exposição da série Ciclos do Eldorado (2015/2016) marcou os 40 anos de trajetória artística de Otoni Mesquita, fazendo um resgate dos trabalhos anteriores sobre o Eldorado. Ficou em cartaz, no Museu Amazônico, em Manaus, de dezembro de 2015 até fevereiro de 2016, sendo ainda mais provocativa e instigante comparada as anteriores, reforçando o discurso crítico e reflexivo sobre a ocupação do planeta, sobretudo, na Amazônia. $\mathrm{Na}$ abertura do evento, as "Personas" da primeira exposição transformaram-se em personagens "reais" numa performance interativa junto ao público. A exposição apresentou treze instalações, com o intuito de promover uma reflexão e possível discussão sobre aspectos ambientais e políticos que afetam o cotidiano da sociedade, especialmente a amazonense. Dentre as peças, destaca-se: Buscas e Achados, composta por gravuras e papeis tratados com técnicas mistas; 
Oferendas Saqueadas, com ídolos dourados, cédulas de dinheiro, moedas e um altar, simbolizando o capitalismo e o apagamento das culturas ancestrais e seus símbolos; as instalações Seres do rio de água Doce, Minha terra tem palmeiras, Tapetes da Floresta e a Construção do Deserto, elaboradas com diversos materiais orgânicos, tratam diretamente de questões da degradação ambiental; em Ciclo Gastronômico discute sobre a influência de frutos, folhas, sementes, e outros produtos naturais na culinária universal; e em Promessas de Futuro revela as incertezas sobre o que virá pela frente em nossa sociedade, entre possibilidades sustentáveis e atitudes marcadas pela ignorância ecológica.

Desse modo, ao envolver diversas linguagens artísticas reconfiguradas no tempo e no espaço, o caráter cíclico de sua abordagem temática também pode ser interpretado como signos em transformação. Numa exposição o artista exibe uma gravura que em outra ocasião aparece digitalizada e animada, reconfigurando-se em vídeo-arte; galhos, folhas, pedras e caracóis podem servir como elementos de uma instalação e em outro momento tornam-se composições numa fotografia; da reunião de esculturas surge uma instalação; ou ainda, o que antes aparecia na superfície das telas em tinta acrílica, depois ganha movimento em sudários com motivos indígenas; grafismos que outrora foram experiências de monotipia, em outro momento transformam-se em tatuagens pintadas na pele de performers, e assim sucessivamente.

Diante disso, podemos dizer que a semiose de Ciclos do Eldorado nos mapeia trajetórias ecossistêmicas, configurando e reconfigurando imaginários, por meio de memórias e metamorfoses, construindo novas cartografias sígnicas, numa transformação contínua no fluxo comunicativo, com suas inter-relações e interdependências.

\section{CONSIDERAÇÕES FINAIS}

O processo cíclico da temática trabalhada por Otoni Mesquita pode ser associado ao que Salles (2010) chama de "estética da continuidade", que é a busca pessoal de um artista, sobre a qual nem sempre é possível precisar o ponto de origem. Entretanto, são indagações complexas que vão ganhando diferentes narrativas com desdobramentos que podem ser inesgotáveis, pois o conjunto da obra de um artista reflete processos de transformação. Na arte contemporânea, a obra se dá no estabelecimento de relações e interdependências, uma permanente rede em construção, como um ecossistema comunicacional.

Percebe-se que o processo de criação de Otoni Mesquita é caracterizado pela ressignificação de imagens que em determinado momento ou contexto se apresentam sob 
determinada forma e depois são transformadas. As diferentes tendências e linguagens orbitam no mesmo campo gravitacional que dá uma espécie de unicidade ou identidade harmônica na elaboração de um "ideal artístico", que por sua vez é influenciado por princípios éticos e estéticos, além de se manifestar num forte "discurso ecológico", reforçando sua postura política crítica em relação ao processo histórico e suas reverberações na sociedade contemporânea. Podemos dizer, que esse conjunto de atitudes configurem o que Salles (2010) compreende como o "projeto poético do artista".

São princípios relativos à singularidade do artista: planos de valores, formas de representar o mundo, gostos e crenças que regem seu modo de ação. Esse projeto está inserido no espeço e no tempo da criação, que inevitavelmente afetam o artista. A busca pela concretização desse projeto é contínua, daí ser sempre incompleta; ao mesmo tempo, o próprio projeto altera ao longo do tempo. (SALLES, 2010, p. 46).

Portanto, visto por um ângulo mais aberto, o processo criativo-comunicativo que gira em torno da arte crítica e da postura ética de Otoni Mesquita impulsiona inúmeras percepções e desdobramentos sobre processos socioculturais, pois o artista, que é um remanescente da geração de vanguarda de intelectuais amazonenses no período da ditadura militar, mantém-se como um símbolo de resistência, fazendo arte para a transformação social e política.

\section{REFERÊNCIAS}

COLFERAI, S. Um jeito amazônida de ser mundo. A Amazônia como metáfora do ecossistema comunicacional: uma leitura do conceito a partir da região. 2014. 226 f. Tese (Doutorado em Sociedade e Cultura na Amazônia) - Universidade Federal do Amazonas, Manaus, 2014.

FRITAS, I. Tramas Comunicativas da Cultura. A Dança no Jornalismo Impresso em Manaus (1980-2000). 2010. 477 f. Tese (Doutorado em Comunicação e Semiótica) Pontifícia Universidade Católica de São Paulo, São Paulo, 2010.

GREINER, C. O corpo, pistas para estudos indisciplinares. São Paulo: Annablume, 2005.

MLODINOW, L. Subliminar: como o inconsciente influencia nossas vidas. Rio de Janeiro: Zahar, 2013.

MONTEIRO, G.; ABBUD, M.; PEREIRA, M. (Org.). Estudos e perspectivas dos ecossistemas na comunicação. Manaus: Edua/UFAM, 2012.

MONTEIRO, G.; DANTAS, J. Ecossistemas comunicacionais: uma visão prática. In: MONTEIRO, G.; ABBUD, M.; PEREIRA, M. (Org.). Estudos e perspectivas dos ecossistemas na comunicação. Manaus: Edua/UFAM, 2012. p. 213-225. 


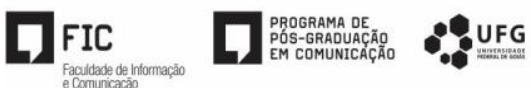

PEREIRA, M. Ecossistemas comunicacionais: uma proposição conceitual. In: MALCHER, M.; SEIXAS, N.; LIMA, R.; FILHO, O. (Org.). Comunicação Midiatizada na e da Amazônia. Belém: FADESP, 2011. p. 49-63.

PAES LOUREIRO, J. Cultura amazônica: uma poética do imaginário. Manaus: Editora Valer, 2015.

PÁSCOA, L. As artes plásticas no Amazonas: o Clube da Madrugada. Manaus: Valer, 2011.

SALLES, C. A. Arquivos de criação: arte e curadoria. Vinhedo: Horizonte, 2010. 